\title{
Programming maternal and child overweight and obesity in the context of undernutrition: current evidence and key considerations for low- and middle-income countries
}

\author{
Lindsay M Jaacks ${ }^{1, *}$, Justine Kavle ${ }^{2,3,4}$, Abigail Perry ${ }^{5}$ and Albertha Nyaku ${ }^{3}$ \\ 'Department of Global Health and Population, Harvard T.H. Chan School of Public Health, Harvard University, 665 \\ Huntington Avenue, Building 1, Room 1221, Boston, MA 02115, USA: ${ }^{2}$ Maternal and Child Survival Program, \\ Washington, DC, USA: ${ }^{3}$ Maternal, Newborn, Child Health and Nutrition (MNCHN) Program, PATH, Washington, \\ DC, USA: ${ }^{4}$ Department of Prevention and Community Health, Milken Institute School of Public Health, George \\ Washington University, Washington, DC, USA: ${ }^{5}$ Department for International Development, London, UK
}

Submitted 11 April 2016: Final revision received 3 November 2016: Accepted 8 November 2016: First published online 9 January 2017

\begin{abstract}
The goals of the present targeted review on maternal and child overweight and obesity were to: (i) understand the current situation in low- and middle-income countries (LMIC) with regard to recent trends and context-specific risk factors; and (ii) building off this, identify entry points for leveraging existing undernutrition programmes to address overweight and obesity in LMIC. Trends reveal that overweight and obesity are a growing problem among women and children in LMIC; as in Ghana, Kenya, Niger, Sierra Leone, Tanzania and Zimbabwe, where the prevalence among urban women is approaching $50 \%$. Four promising entry points were identified: (i) the integration of overweight and obesity into national nutrition plans; (ii) food systems (integration of food and beverage marketing regulations into existing polices on the marketing of breast-milk substitutes and adoption of policies to promote healthy diets); (iii) education systems (integration of nutrition into school curricula with provision of high-quality foods through school feeding programmes); and (iv) health systems (counselling and social and behaviour change communication to improve maternal diet, appropriate gestational weight gain, and optimal infant and young child feeding practices). We conclude by presenting a step-by-step guide for programme officers and policy makers in LMIC with actionable objectives to address overweight and obesity.
\end{abstract}

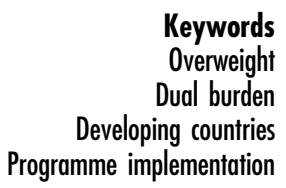

Keywords

Overweight

Dual burden

Programme implementation
The increasing prevalence of overweight and obesity among women and children in low- and middle-income countries (LMIC) represents hindered progress on maternal and child health, and has important implications for future economic development ${ }^{(1)}$. Between 2006 and 2015, the cost of lost economic productivity due to obesity-related CVD and diabetes in LMIC was estimated to be \$US 84 billion $^{(2)}$. Moreover, obesity-related disability-adjusted life years in LMIC have increased dramatically over the past two decades: from 518 per 100000 people in 1990 to 985 per 100000 people in 2013, which translates into a $90 \%$ relative increase in disability-adjusted life years ${ }^{(3)}$. Given that one of the targets for the Sustainable Development Goal 2,
'End Hunger', is to end all forms of malnutrition, strategies to address both undernutrition and overweight and obesity globally are urgently needed.

The purpose of the present targeted review on maternal and child overweight and obesity was not to systematically review trends in the prevalence of maternal and child overweight and obesity in LMIC. Instead, we aimed to conduct a targeted review in order to: (i) understand the current situation in LMIC with regard to recent trends and context-specific risk factors; and (ii) building off this, identify entry points for leveraging existing undernutrition programmes to address overweight and obesity in LMIC. We focused on low-income and lower-middle-income countries, 
particularly in sub-Saharan Africa, where large development agencies currently support nutrition programmes. The overall goal is to spark evidence-based action in this important and almost entirely neglected topic in global nutrition.

\section{Trends in overweight and obesity among women and children}

According to the 2016 Global Nutrition Report, 'obesity and overweight are now a staggering global burden, ${ }^{(4)}$. A recent analysis of Demographic and Health Surveys found that in urban Mauritania, over half of reproductive-aged women are overweight or obese, and the prevalence in urban areas of Ghana, Kenya, Niger, Sierra Leone, Tanzania and Zimbabwe is approaching $50 \%{ }^{(5)}$. The annualized change in prevalence from approximately 2000 to 2010 among women in urban areas of Bangladesh, Ghana, Malawi, Nepal, Niger, Rwanda, Zambia and Zimbabwe was at least $1.00 \%{ }^{(5)}$, meaning that if trends continue, the prevalence of overweight in urban areas of these countries will increase by $10 \%$ over the next decade. The prevalence of overweight and obesity is lower in rural areas compared with urban areas in most $\mathrm{LMIC}^{(5)}$. However, looking at trends over time, the recent rate of increase in overweight and obesity in several countries (e.g. Burkina Faso, Kenya, Uganda and Zimbabwe) is greater in rural areas compared with urban areas ${ }^{(5)}$. Thus, while rural-urban disparities persist, the gap is narrowing in some countries.

While the most recent prevalence of overweight and obesity among adolescent girls was much lower than that among women, trend data indicate that the prevalence in adolescent girls is increasing over time in many countries $^{(6)}$. With respect to children under 5 years of age, Malawi, Mozambique, Nigeria, Rwanda and Zambia have a prevalence of overweight greater than $7 \%^{(7)}$, which is the global nutrition target for childhood overweight set by the $\mathrm{WHO}^{(8)}$.

\section{Context-specific risk factors for overweight and obesity}

Risk factors were identified via reviewing the seminal Lancet series on obesity (2011 and 2015) and the Bellagio Conference on Program and Policy Options for Preventing Obesity in Low- and Middle-Income Countries ${ }^{(9-11)}$. Shifts in dietary intake and physical activity resulting from economic development, urbanization and globalization of the food system are thought to be key drivers of the global obesity epidemic, and are described in detail elsewhere ${ }^{(9,10,12)}$. Several risk factors may be of particular importance in the context of vulnerable populations living in LMIC and are discussed in detail here. These include: (i) maternal nutrition and appropriate gestational weight gain; (ii) infant and young child nutrition and healthy growth trajectories; (iii) value and social standing; (iv) time and effort for food preparation; and (v) cultural beliefs about body size.

\section{Maternal nutrition and appropriate gestational weight gain}

Few studies have explored gestational weight gain knowledge and beliefs in LMIC. One study, conducted in Nigeria, found that $40 \cdot 1$ and $35.4 \%$ of mothers were classified as overweight and obese, respectively, according to pre-pregnancy $\mathrm{BMI}^{(13)}$. However, none of the obese mothers perceived themselves as obese ${ }^{(13)}$. In contrast, $32.0 \%$ of the overweight mothers perceived themselves as overweight, and those who perceived themselves as overweight were more likely to gain the recommended amount of weight during pregnancy ${ }^{(13)}$. A qualitative study in Egypt found that women were not aware of and had no concept of appropriate gestational weight gain due to a lack of counselling by health-care providers ${ }^{(14)}$. Given that maternal obesity and excess gestational weight gain have been associated with increased adiposity in offspring, largely in studies conducted in developed countries ${ }^{(15)}$, this is an important research gap in LMIC. In addition, insufficient maternal intakes of energy and micronutrients have been associated with increased adiposity in offspring, particularly female offspring - as reviewed by Yang and Huffman ${ }^{(16)}$ and Christian and Stewart $^{(17)}$. For example, maternal energy intake of less than $3766 \mathrm{~kJ} / \mathrm{d}(900 \mathrm{kcal} / \mathrm{d})$ during the Dutch famine of 1944-1945 was associated with greater fat deposition in female offspring (average age at follow-up approximately 60 years), but not males ${ }^{(18)}$. Two secondary analyses of trials, one in $\mathrm{Nepal}^{(19)}$ and one in Peru ${ }^{(20)}$, found increased linear growth (Nepal) and lean body mass (Peru), and, in the case of Nepal, decreased adiposity, among offspring of women who received $\mathrm{Zn}+\mathrm{Fe}+$ folic acid during pregnancy $v$. offspring of women who received $\mathrm{Fe}+$ folic acid.

\section{Infant and young child nutrition and bealthy growth trajectories}

Fetal growth and growth in the first 2 years of life are important predictors of adult weight status ${ }^{(21)}$. A recent analysis of the Consortium on Health Oriented Research in Transitional Societies (COHORTS) study, which includes five LMIC (Brazil, Guatemala, India, the Philippines and South Africa), found that birth weight was more strongly associated with adult lean body mass than with adult fat mass ${ }^{(22)}$. Similarly, a study in Pune, India, found that the small birth size of babies was largely due to reduced skeletal muscle rather than reduced body fat ${ }^{(23)}$, and a study in New Delhi, India, found that birth weight was positively associated with adult lean body mass but not adult central adiposity ${ }^{(24)}$. In contrast, with respect to postnatal growth, a meta-analysis of fifteen studies reported an $84 \%$ increase in risk of obesity at 10 years of age per 0.67 SD gain of weight in infancy ${ }^{(25)}$. Data from the COHORTS study suggest that both faster relative weight gain and faster linear growth among children were associated with increased risk of adult overweight ${ }^{(26)}$. However, it is important to note that the magnitude of these associations in the COHORTS study was small: a 1 SD change in weight gain up 
to 12 or 24 months predicted less than a $1 \%$ change in adult body composition ${ }^{(22)}$. Together, these results suggest two key points:

1. improved birth weight, as an indicator of fetal growth, may be protective against overweight via building adult lean body mass; and

2. the known benefits of growth in the first 2 years of life on health and function ${ }^{(27)}$ and the known adverse consequences of growth faltering in early life on adult stature $^{(28)}$ are likely to outweigh any negative effects on adult obesity resulting from rapid 'catch-up' growth during this period ${ }^{(26)}$.

While several systematic reviews and meta-analyses, including a WHO-led review ${ }^{(29)}$, have found protective effects of breast-feeding on obesity in developed countries, including the USA, Canada, UK, Germany, Australia, New Zealand and former Czechoslovakia, there is a need for additional studies to provide stronger evidence because these studies did not account for publication bias and residual confounding by maternal socio-economic status and lifestyle habits ${ }^{(30)}$. One randomized controlled trial on promotion of exclusive breast-feeding in Belarus did not find any effect on childhood obesity $^{(31)}$. A significant evidence gap remains on whether any relationship between breast-feeding and overweight exists in LMIC. A study in Brazil did not find a significant association between breast-feeding duration and $\mathrm{BMI}^{(32)}$, while a study in India found only a weak association between breast-feeding duration and BMI and no association with skinfold thickness ${ }^{(33)}$. Regardless of whether breast-feeding is or is not protective against overweight, the strong evidence supporting other benefits of breast-feeding ${ }^{(34)}$ warrants continued support of breast-feeding recommendations ${ }^{(35)}$.

With regard to complementary feeding, the limited data available from LMIC suggest that suboptimal complementary feeding practices are common and include energy-dense, nutrient-poor foods. For example, a survey of 700 mothers of 6- to 18-month-old infants in Ibadan, Nigeria, found that, on a daily basis, $65.0 \%$ regularly gave biscuits to their infants, $16 \cdot 1 \%$ gave soft drinks and $9.6 \%$ gave commercial fruit juice ${ }^{(36)}$. In addition, $57 \cdot 0 \%$ of mothers sweetened their infants' pap (maize-based porridge) with sugar ${ }^{(36)}$. In a study of 4299 children living in two slums outside Nairobi, Kenya, $41 \%$ had received sweetened/flavoured water in the first 6 months of life ${ }^{(37)}$. With regard to breast-milk substitutes, high-protein infant formulas in the first 2 years of life have been associated with increased adiposity in childhood relative to control formulas in several randomized controlled trials conducted in Europe ${ }^{(38,39)}$, but this relationship has not been explored in LMIC.

\section{Value and social standing}

Few studies have explored drivers of food choice in LMIC. One qualitative study, conducted in rural Kerala, India, found that the two most important drivers of food choice at the household level were affordability and taste preferences of the children and husband ${ }^{(40)}$. For example, one woman said, '... we use lot of oil ... difficult to reduce, he [husband] likes lot of fried things ${ }^{(40)}$. Processed foods were perceived as 'higher value' based on the media's portrayal of these foods as necessary for healthy growth and development of children $^{(40)}$. This can often lead to higher-than-affordable expenditures on these foods: for example, one woman said, '... spend an average four-thousand rupees on food per month ... have to spend an extra one to two thousand on biscuits and powder items [health drinks] for small children in the house ${ }^{,(40)}$. Similarly, expensive foods such as restaurant foods were considered 'better' than foods that were cheaper and could be prepared at home ${ }^{(40)}$. A study in Nigeria also reported that consumption of fast foods was associated with higher social standing ${ }^{(41)}$. In contrast, in Egypt, processed junk foods for children were not perceived as expensive and were within economic reach of most families in both rural and urban areas ${ }^{(42)}$. Also in Egypt, junk food consumption was not just an issue among children; mothers and other family members also consumed these foods ${ }^{(42)}$.

\section{Time and effort for food preparation}

As women enter the workforce, their time to prepare food becomes limited. For example, in the aforementioned qualitative study conducted in rural Kerala, India, one mother stated: 'I come back from work and I just try to make something fast for the children as they are hungry by then ${ }^{,(40)}$. In contrast, in lower-income households in these communities in rural Kerala, the limitation was affordability, not time: 'Most people complain that it takes a lot of time and effort to cut vegetables. That is only for those who don't have time. Here, we have time, but no vegetables and no money to buy it ${ }^{(40)}$. In Egypt, reducing consumption of junk food is challenging because mothers often give these foods out of convenience, stating that, 'I have no time to cook for my children', 'I have no free time' and 'I felt lazy' ${ }^{(42)}$. Moreover, data from Egypt suggest that older siblings care for younger children and play an important role in feeding young children when mothers are away from home ${ }^{(42)}$. A recent analysis of data from Cambodia found that women increasingly have sales and service jobs, especially in urban settings, and that this is linked to overweight and obesity, potentially through time pressures in addition to increased sedentary time ${ }^{(43)}$. Further research is needed that focuses on the impact of women entering the workforce on weight status in LMIC and on potential mechanistic pathways other than sedentary time, such as stress, time pressures and economic independence.

\section{Cultural beliefs about body size}

Studies in some LMIC indicate that cultural beliefs about body size may be an important barrier to programmes aimed at preventing overweight and obesity. For example, in urban 
areas of Pakistan, where $64 \%$ of adult study participants were overweight, most did not perceive themselves as overweight ${ }^{(44,45)}$. Two cross-sectional studies of overweight female university students residing in urban Pakistan reported that up to $18 \%$ believed they were of normal weight ${ }^{(45,46)}$. Findings also reveal that a Pakistani adult who is happy or does not think about his/her weight is six times more likely to misperceive him/herself as not being overweight $^{(44)}$. In some sub-Saharan African countries, such as Nigeria, obesity is perceived as a sign of 'power, respect, and an evidence of good living ${ }^{(41)}$. Further research is needed to understand beliefs relating to overweight and obesity, particularly in areas with a high prevalence of HIV/AIDS, as there may be a stigma attached to thinness in these contexts ${ }^{(47)}$.

\section{Entry points for overweight and obesity programming within existing undernutrition programmes}

Based on our analysis of context-specific risk factors, we developed a conceptual framework (Fig. 1) that highlights programmes and policies that could be prioritized to address overweight and obesity in LMIC. The WHO's Global Action Plan for the Prevention and Control of Noncommunicable Diseases 2013-2020 ${ }^{(48)}$, the WHO report Population-Based Approaches to Childhood Obesity Prevention $^{(48,49)}$ and the WHO report Interventions on Diet and Physical Activity: What Works ${ }^{(50)}$ were also consulted when developing the conceptual framework. The overlap between aspects of this framework and existing nutrition programmes largely focused on undernutrition is presented in Table 1 . The four promising entry points identified were as follows:

1. integration of overweight and obesity into national nutrition plans;

2. food systems (integration of food and beverage marketing regulations into existing polices on the marketing of breast-milk substitutes and adoption of policies to promote healthy diets);

3. education systems (integration of nutrition into school curricula with provision of high-quality foods through school feeding programmes); and

4. health systems (counselling and social and behaviour change communication to improve maternal diet, appropriate gestational weight gain, and optimal infant and young child feeding practices).

\section{Integration of overweight and obesity into national nutrition plans}

Strong nutrition governance, including setting SMART (specific, measureable, achievable, relevant and time-bound) targets, has been linked to achieving undernutrition goals such as stunting ${ }^{(4,51)}$. Few LMIC address overweight and obesity in their national nutrition plans. Kenya is an example of one such country. The Kenyan National Nutrition Action Plan (2012-2017) outlines specific activities to address the increase in overweight and obesity in Kenya, including the following: review, develop and disseminate a comprehensive strategy and guidelines for preventing, managing and controlling nutrition-related non-communicable diseases; train service providers and create public awareness on the importance of preventing, managing and controlling nutrition-related non-communicable diseases; scale up community screening of BMI and waist circumference; and improve nutrition in schools. Kenya's 2013 National Maternal, Infant, and Young Child Nutrition Policy Guidelines also state that childhood obesity is an emerging public health problem.

\section{Food systems}

The food system is a critical underlying determinant of dietary intake, and includes food production, distribution, processing, packaging, marketing and retail. Two aspects of food systems that are particularly important for addressing

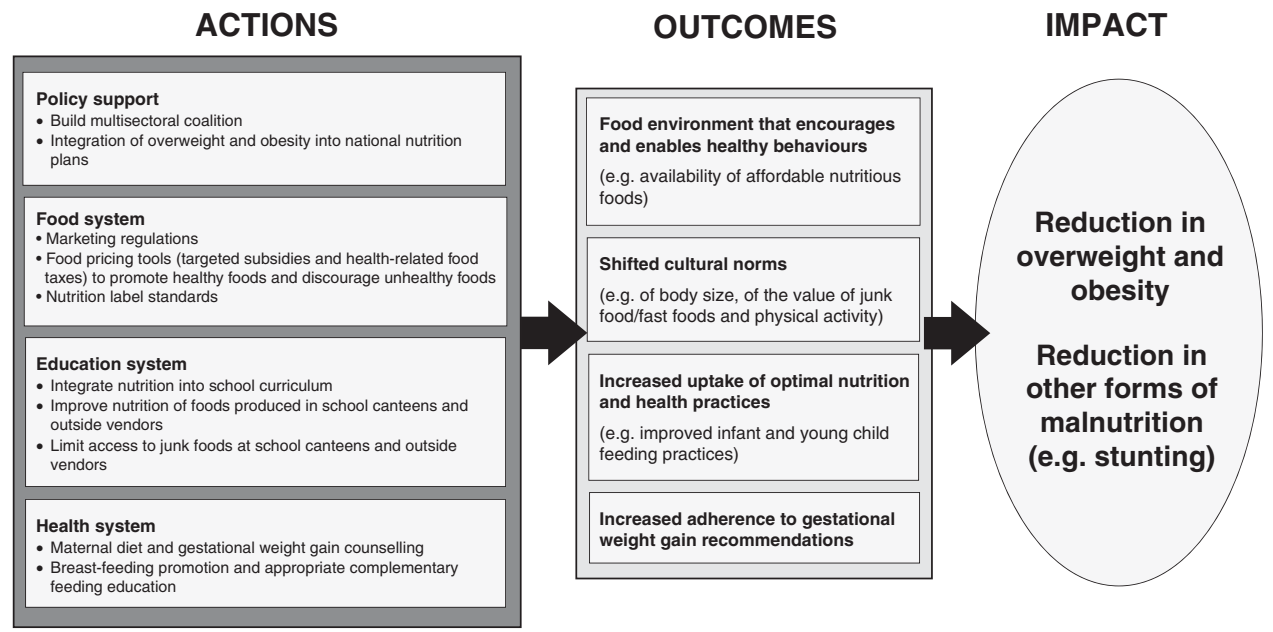

Fig. 1 Framework illustrating how specific actions can help to achieve meaningful improvements in outcomes such as increased uptake of optimal nutrition and health practices, and how they impact overweight and obesity and other forms of malnutrition 
Table 1 Examples of programmatic approaches to address overweight and obesity in low- and middle-income countries in the context of existing nutrition programmes largely focused on undernutrition

\begin{tabular}{|c|c|c|c|}
\hline & Food systems & Education systems & Health systems \\
\hline Existing nutrition programmes & $\begin{array}{l}\text { - Restrict marketing of breast- } \\
\text { milk substitutes } \\
\text { - Invest in food distribution } \\
\text { infrastructure } \\
\text { - Increased access to legumes/ } \\
\text { pulses and grains high in } \\
\text { protein and micronutrients } \\
\text { - Public procurement and } \\
\text { distribution of fruits and } \\
\text { vegetables }\end{array}$ & $\begin{array}{l}\text { - Schools should develop dietary guidelines } \\
\text { that promote and provide healthy foods } \\
\text { and, where feasible, provide healthy } \\
\text { breakfast and/or lunch to students }\end{array}$ & $\begin{array}{l}\text { - Counselling by community health workers on appropriate } \\
\text { dietary intake during pregnancy } \\
\text { - Breast-feeding promotion } \\
\text { - Appropriate complementary feeding that emphasizes } \\
\text { quantity, quality and diversity of foods according to age, and } \\
\text { ensures intra-household allocation of foods to infants and } \\
\text { young children }\end{array}$ \\
\hline $\begin{array}{l}\text { Integration of overweight and } \\
\text { obesity }\end{array}$ & $\begin{array}{l}\text { - Restrict marketing of unhealthy } \\
\text { foods to children } \\
\text { - Food-based dietary guidelines } \\
\text { - Nutrition label standards }\end{array}$ & $\begin{array}{l}\text { - School curricula should include what } \\
\text { constitutes a 'healthy diet', the health } \\
\text { consequences of overweight/obesity and } \\
\text { the importance of physical activity } \\
\text { - Adolescent girls are an important target } \\
\text { population } \\
\text { - Schools should reduce access to sugary, } \\
\text { high-fat snacks and beverages } \\
\text { - The importance of a healthy weight should } \\
\text { also be discussed in preparation for } \\
\text { pregnancy, with non-pregnant women and } \\
\text { adolescents, through community channels } \\
\text { or schools }\end{array}$ & $\begin{array}{l}\text { - Develop overweight and obesity polices and guidelines and } \\
\text { provide budgetary allocations for implementation at district } \\
\text { and health facility levels } \\
\text { - Integrate overweight into pre-service and in-service training } \\
\text { curricula of health providers } \\
\text { - Incorporate promotion of 'healthy diets' in nutrition } \\
\text { behaviour change activities } \\
\text { - Heath-care providers should provide counselling on mater- } \\
\text { nal diet and appropriate gestational weight gain during } \\
\text { antenatal care } \\
\text { - Counselling should be based on an understanding of } \\
\text { cultural beliefs and food choice related to high-energy foods } \\
\text { (i.e. sugary foods and fried foods) and nutritious foods } \\
\text { (i.e. fruits and vegetables) } \\
\text { - Counsel mothers, caregivers, family members and } \\
\text { influential community members to feed children } \\
\text { appropriately and to not consume junk foods } \\
\text { - Avoid providing sugar-sweetened beverages during com- } \\
\text { munity/mothers' support group sessions and postnatal } \\
\text { care visits } \\
\text { - Develop monitoring and evaluation indicators and targets } \\
\text { for national, district/health facility and community levels } \\
\text { - Include overweight indicators in national development plans }\end{array}$ \\
\hline
\end{tabular}


overweight and obesity in LMIC include: (i) implementing the WHO recommendations on marketing of food and beverages to children; and (ii) policies that promote healthy diets and discourage unhealthy diets.

According to the $\mathrm{WHO}$, introducing policies that reduce the marketing of foods high in saturated fat, trans-fat, free sugars or salt to children is likely to be one of the most cost-effective interventions available to governments to address obesity ${ }^{(49,52)}$. Three upper-middle-income countries (Brazil, Thailand and South Africa) have drafted resolutions that address food marketing to children ${ }^{(53)}$, but these policies are currently suspended in both Brazil ${ }^{(54)}$ and South Africa ${ }^{(55)}$. Many LMIC have already adopted policies that regulate food industry marketing of breast-milk substitutes ${ }^{(56)}$ and lessons learned from that process may prove to be informative for adopting resolutions to regulate marketing of unhealthy foods to children ${ }^{(57)}$. Lessons learned from high-income countries that have already adopted marketing restrictions could also be useful to policy makers in LMIC. For example, in the UK, where marketing restrictions have been in place since 2007 , an analysis of advertising exposure to high-fat, -salt or -sugar products among children under 16 years of age found almost universal adherence to the restrictions, but that exposure did not change before and after the adoption of the restrictions ${ }^{(58)}$, suggesting that stronger restrictions targeting a wider range of advertisements is needed.

The NOURISHING framework developed by World Cancer Research Fund International is a tool that policy makers in LMIC can use for guidance on developing a comprehensive policy package to promote healthy diets and discourage unhealthy diets ${ }^{(59)}$. Few LMIC have adopted policies consistent with the NOURISHING framework. This was made evident at the 2013 Bellagio Conference on Program and Policy Options for Preventing Obesity in Low- and Middle-Income Countries ${ }^{(9)}$ : of the thirteen countries represented at the Conference, only two were lower-middle-income countries (India and Bangladesh) and none were low-income countries. Nevertheless, some LMIC policies addressing the food system within the NOURISHING framework are worth mentioning here.

Several LMIC have policies that promote fruit and vegetable production; many were originally adopted in order to address micronutrient deficiencies, but now play the additional role of overweight and obesity prevention ${ }^{(60)}$. Several LMIC have also adopted food-based dietary guidelines. For example, the Dietary Guidelines for the Brazilian Population, which, in conjunction with the National Food and Nutrition Security Policy and National Health Promotion Policy, aim to promote healthy eating and the prevention of malnutrition including micronutrient deficiencies and overweight and obesity ${ }^{(61)}$. These Guidelines could be adapted to other countries as part of a comprehensive policy package to address malnutrition, including overweight and obesity.

In 2005, the Ghana Ministry of Health adopted the Regenerative Health and Nutrition Program with the primary objective of promoting healthy lifestyles, including diet and daily physical activity. Since 2006, over 50000 community members have been trained, who in turn educate other community members. However, analysis of data from before and after implementing the programme shows an overall decline in unhealthy behaviours only among highly educated individuals ${ }^{(62,63)}$. Moreover, a panel in the 2016 Global Nutrition Report suggests that the 2012 National Policy for the Prevention and Control of Chronic Non-Communicable Diseases in Ghana has not been 'operationalized in any way' (4).

Finally, nutrition labelling has been recommended as a policy tool for addressing unhealthy food environments ${ }^{(49)}$. However, the impact of interpretive nutrition labelling policies on food purchasing patterns has been evaluated only in the UK, where there was 'no discernible effect on the relative healthiness of consumer purchases ${ }^{, 64)}$.

\section{Education systems}

A systematic review including twenty-two studies from LMIC found that school-based interventions have the potential to improve diet and physical activity behaviours and decrease $\mathrm{BMI}$ in these contexts ${ }^{(65)}$. Schools offer a unique opportunity to change norms around nutritional practices and healthy body weights. The review also found that involving multiple stakeholders and integrating educational activities into existing school curricula worked best ${ }^{(65)}$.

Two cities in Africa - Ouagadougou, Burkina Faso and Cotonou, Benin - have piloted the WHO Nutrition-Friendly School Initiative, which is a framework for the prevention of the double burden of undernutrition and overweight among schoolchildren. There are five conditions that must be met for a school to be considered nutrition-friendly, beginning with the formation of a School Nutrition Committee that involves key stakeholders. The School Nutrition Committee is responsible for meeting these five conditions and for monitoring and evaluation of the programme: (i) a written school policy on nutrition; (ii) building awareness and capacity of the surrounding community as they relate to nutrition; (iii) school curriculum adaptation to include nutrition; (iv) school environment that supports optimal nutrition and health; and (v) school nutrition and health services ${ }^{(66)}$. In Ouagadougou, sensitizing communities to nutrition was identified as a priority for half of the schools ${ }^{(67)}$, and many involved in the initiative felt that these policies should be implemented at the national level rather than the school level ${ }^{(67)}$. Piloting the Nutrition-Friendly School Initiative in 2007 in New Delhi, India, an initial assessment found no written nutrition policies in the four participating schools and no integration of nutrition and health into the school curriculum ${ }^{(68)}$.

A 6-month nutrition education programme focused on nutrition, physical activity, non-communicable diseases and healthy cooking practices was implemented in both private and public schools of three northern Indian cities 
(New Delhi, Agra and Jaipur) ${ }^{(69)}$. At baseline, only 25-55\% of students considered deep-fried Indian snack foods to be junk foods and $25-35 \%$ of students thought that consuming butter improves bone strength and health ${ }^{(69)}$. Results of the intervention were promising: a pre/post statistical comparison of responses of a random subset of students to a questionnaire on health and nutrition-related knowledge found significant improvements in both private and public schools, particularly on questions relating to physical activity and healthy cooking practices ${ }^{(69)}$.

Government policies to support the provision of healthy foods in schools could build off the Purchase from Africans for Africa programme (Ethiopia, Malawi, Mozambique, Niger and Senegal), which encourages the consumption of non-processed, nutrient-dense foods (cereals, pulses and legumes, fruits, vegetables and animal products $)^{(70)}$. For example, as part of the programme, Malawi smallholder farmers now provide staple grains, groundnuts, bananas and fish to ten primary schools where enrolment has increased by $15 \%{ }^{(71)}$. Prevention of overweight and obesity could be an important co-benefit of such programmes.

\section{Health systems}

Currently, programming during routine contact points with women and children at the community and facility levels in LMIC focuses on reducing undernutrition without consideration of overweight and obesity. However, these are unique opportunities to address maternal diet and weight gain during pregnancy, as well as infant and young child feeding practices that are important risk factors for overweight and obesity.

Few studies in LMIC have evaluated the impact of antenatal counselling on appropriate gestational weight gain. In Nigeria, receiving information on gestational weight gain from multiple health-care providers was significantly associated with increased levels of maternal knowledge on risks of inappropriate weight gain ${ }^{(13)}$. However, although $57 \%$ of Nigerian mothers were counselled on the risks associated with excess weight gain, many mothers were not aware of the recommended amount of weight gain during pregnancy ${ }^{(13)}$. In Egypt, women were also not counselled on weight gain during pregnancy and had little understanding of the appropriate amount of weight gain ${ }^{(14)}$. A small study of women attending a clinic in Accra, Ghana, found that they were willing to reduce their body size in order to reduce the risk of obesity-related illnesses such as hypertension, diabetes, CVD and myocardial infarction ${ }^{(72)}$. Education, income, marital status and number of children did not influence their response, although women who were younger than 50 years of age tended to be more likely to report being willing to reduce their body size to improve health $^{(72)}$. Thus, providing counselling on maternal diet and weight gain during pregnancy during antenatal care can potentially address overweight and obesity in LMIC.
Another important point of entry is existing health promotion-based interventions such as complementary feeding interventions for infants and young children. Health-care providers and families need to understand healthy $v$. unhealthy weight gain and can learn to monitor excessive and/or rapid weight gain within the context of undernutrition programming. In addition, families should be advised that junk foods are detrimental to the growth of children and the entire family's health, and providers should be trained to provide nutrition counselling for families during routine growth monitoring visits ${ }^{(73)}$. A recent study in Egypt used Trials for Improved Practices (TIPs) methodology to address poor infant and young child feeding practices over the course of three home visits (Fig. 2) ${ }^{(42)}$. During the first visit, researchers discussed behaviours, practices and motivations for infant and young child feeding with mothers, focusing on junk foods. During the second visit, mothers jointly decided with the research team what specific feeding practices they would be willing to try over a one-week period. During the third and final visit, mothers discussed their experiences with TIPs: which recommended practices worked, which did not work and any modifications that were made. Results supported the importance of reducing junk food consumption keeping cultural influences and beliefs in mind when designing interventions.

\section{Research gaps}

Important research gaps identified in the present review include:

- Underlying drivers that are shared by all forms of malnutrition.

- Evaluation of the appropriateness of the Institute of Medicine guidelines for weight gain during pregnancy ${ }^{(74)}$ in the context of LMIC.

- Studies on the association between maternal overweight and obesity, gestational weight gain and child health outcomes.

- Studies of the long-term impact of dietary intake during infancy and early childhood on adult overweight and obesity.

- Drivers of food choice, especially among overweight mothers, and how this information can be used to design programmes to engage women and their families.

- The impact of women entering the workforce on weight status in LMIC and potential mechanistic pathways other than sedentary time such as stress, time pressures and economic independence.

- In settings where undernutrition is still prevalent, testing the effectiveness of interventions that integrate infant/child overweight prevention into antenatal/ postnatal care.

- Studies of the potential adverse effects of supplemental feeding programmes on overweight. One analysis of infant feeding programmes in Chile found increases in child 


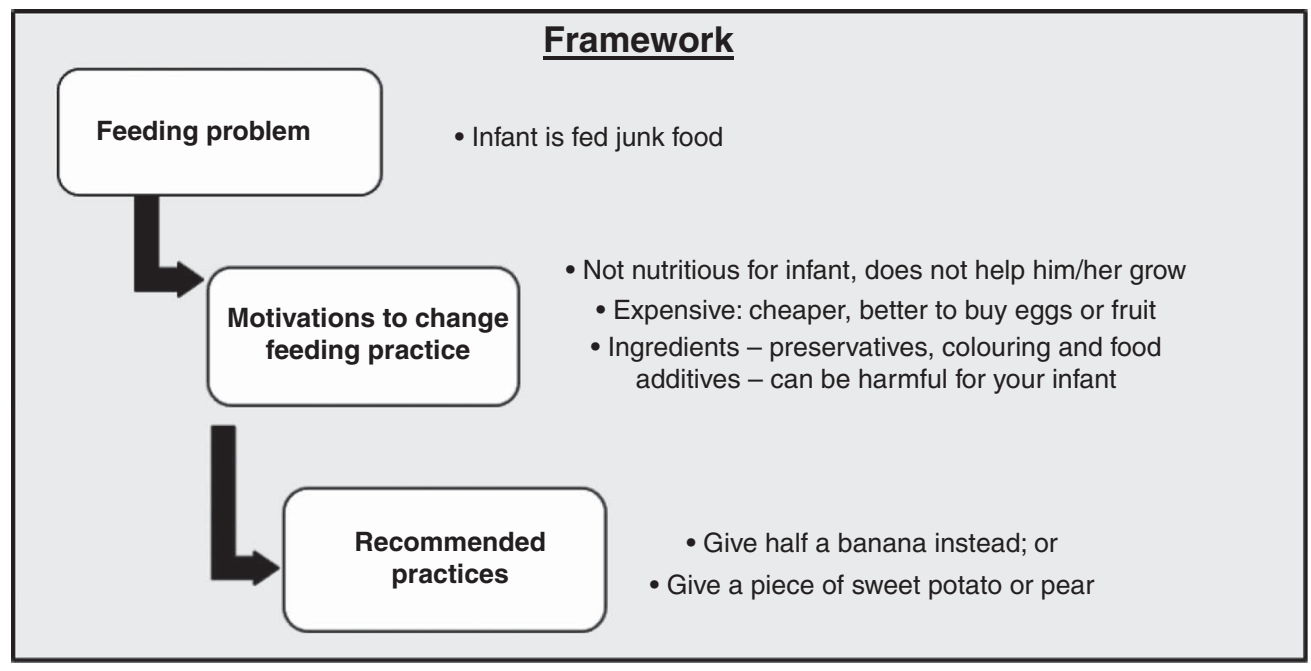

\section{Key findings}

1. Breast-feeding is valued, yet mothers introduce junk foods to young children early Only $25 \%$ of mothers exclusively breast-fed their child in the first 6 months of life. During the first 6 months, some mothers, grandmothers and health-care providers believe children are not 'nourished enough' by breast milk alone and are still hungry. This was the main reason for mothers introducing foods and liquids early. Mothers feed 'light and simple' foods like yoghurt and sugary biscuits as early as 2 months of age

\section{Junk food is a significant part of the diet in the first 2 years of life}

Nearly $30 \%$ of foods fed on a daily basis are junk foods, including potato chips, sponge cakes with cream filling, sugary biscuits, traditional sweets and candy (i.e. chocolate), and sugary drinks

\section{Junk foods, an integral part of children's daily meals, are considered acceptable 'first} foods'

4. Through TIPs, which built on mothers' motivations, most mothers were able to make small, feasible changes in their children's diets

Fig. 2 Example of how Trials for Improved Practices (TIPs) addressed junk food as an infant feeding problem in Egypt

weight-for-age and weight-for-length with little impact on length-for-age ${ }^{(75)}$. A secondary analysis of a randomized controlled trial in Burkina Faso found that women with pre-pregnancy BMI in the highest tertile $\left(21 \cdot 8-28 \cdot 1 \mathrm{~kg} / \mathrm{m}^{2}\right)$ who received lipid-based nutrient supplements gave birth to infants with higher leptin concentrations compared with women with pre-pregnancy BMI in the lowest tertile $\left(15.8-19.7 \mathrm{~kg} / \mathrm{m}^{2}\right)$, which may be a marker of higher neonatal fat mass ${ }^{(76)}$. Thus, supplemental feeding programmes should be targeted to high-risk beneficiaries for energy supplementation (e.g. in humanitarian emergencies and to severely undernourished individuals).

\section{Next steps and conclusion}

Outside extreme conditions, such as war and famine, no country has witnessed a decline in the prevalence of adult obesity ${ }^{(11)}$. Current expert opinion holds that a package of initiatives including multisectoral policies and behaviour change interventions is needed ${ }^{(11)}$. However, the current review has identified many substantial research gaps; this topic remains a severely neglected area of global nutrition. Thus, a key limitation of the review was the fact that there was not enough scientific evidence to support a systematic review and meta-analysis of specific programmes and policies to address overweight and obesity in LMIC. In addition, to date, programmes have struggled with operationalizing overweight and obesity within the context of undernutrition, and programmatic and routine data from health systems are largely nonexistent. The goal of the present targeted review is to guide research and the design and implementation of nutrition programming in the coming years to inform such a systematic review.

The first step to addressing overweight and obesity in LMIC is integration into national nutrition plans and setting SMART targets. Nevertheless, even with these commitments, implementation of overweight and obesity prevention programmes and policies will be a challenge. To aid in this 


\section{Step 1}

Assess the problem

- Determine the prevalence of overweight/obesity among non-pregnant and pregnant women (15-49 years) and children (6-59 months) using DHS data, if available

- Overweight/obesity $\left(B M I \geq 25 \mathrm{~kg} / \mathrm{m}^{2}\right)$ considered a public health problem if the prevalence is $>35 \%$ in adolescents and adults

- Overweight (BMI $\geq 85$ th percentile) considered a public health problem if the prevalence is $>7 \%$ in children

- If recent national data on height and length/weight are not available

- Design national/sub-national cross-sectional survey to collect data on weight and length/height

- Determine what is known about dietary intake patterns

\section{Step 2}

Raise awareness and build a multisectoral coalition

- Raise awareness about the costs to individuals and countries of not addressing overweight/obesity - Build an overweight/obesity coalition including the health, agriculture, food and pharmaceutical sectors among government ministries and agencies, non-governmental organizations, donors, industry and commerce

\begin{tabular}{|c|c|}
\hline Step 3 & Understand how to address the problem \\
\hline \multicolumn{2}{|c|}{$\begin{array}{l}\text { - Conduct focus groups and/or key informant interviews with decision makers in the household and } \\
\text { community } \\
\text { o Understand factors that drive household dietary choices } \\
\text { - Women: cultural practices and perceptions of weight gain during pregnancy, beliefs regarding food choices } \\
\text { and preference during pregnancy and postpartum, and intra-household food allocation in the family } \\
\text { - Infants and young children: facilitating factors and barriers to feeding practices, including age of } \\
\text { introduction of foods/liquids, cultural perceptions and beliefs regarding appropriate foods for infants and } \\
\text { young children, and issues with breast milk sufficiency } \\
\text { - Gain an understanding of cultural beliefs related to specific foods, particularly fruits, vegetables, meat, and } \\
\text { junk foods (high-fat, sugary snacks, desserts and sugar-sweetened beverages) } \\
\text { o Explore dietary change strategies that may be practical at the household and community level }\end{array}$} \\
\hline Step 4 & $\begin{array}{l}\text { Develop social and behaviour change communication messages } \\
\text { and implementation plan }\end{array}$ \\
\hline $\begin{array}{l}\text { - Integrate messaging c } \\
\text { - Ensure antenatal care } \\
\text { - Ensure that infants an } \\
\text { - Develop implementati } \\
\text { - Identify priorities, resp } \\
\text { - Identify specific object } \\
\text { - Identify potential collal } \\
\text { - Review existing progr } \\
\text { rapid weight gain durir } \\
\text { - Determine staffing anc } \\
\text { - Develop a monitoring } \\
\text { and/or wasting }\end{array}$ & $\begin{array}{l}\text { lithy diets into existing education programmes aimed at children and mothers } \\
\text { messaging on maternal diet and appropriate weight gain during pregnancy } \\
\text { ung children are eating family foods and not consuming processed foods and } \\
\text { lans that are culturally relevant and feasible: } \\
\text { bilities and time frames for completion } \\
\text { and key interventions } \\
\text { ing groups } \\
\text { es and develop overweight/obesity prevention activities (i.e.monitoring } \\
\text { st } 2 \text { years of life) } \\
\text { ding for implementing activities } \\
\text { evaluation plan that also fits in with monitoring of underweight, stunting }\end{array}$ \\
\hline
\end{tabular}

Fig. 3 Step-by-step implementation guide to address overweight and obesity in low- and middle-income countries (DHS, Demographic and Health Survey)

process, we have developed a four-step implementation guide for programme officers and policy makers in LMIC (Fig. 3): (i) assess the problem; (ii) raise awareness and build a multisectoral coalition; (iii) understand how to address the problem; and (iv) develop social and behaviour change communication messages and an implementation plan.

The 2016 Global Nutrition Report concluded that in low-income countries, the traditional issues of wasting, stunting and micronutrient deficiencies persist in the face of rising overweight and obesity ${ }^{(4)}$. Integration of efforts to address overweight and obesity within existing programmes focused on undernutrition is needed to maintain gains in maternal and child health in $\mathrm{LMIC}^{(1)}$.
The food system, education system and health system could all be leveraged in the development of comprehensive programmes and policies to address all forms of malnutrition.

\section{Acknowledgements}

Financial support: This work was supported by UK aid from the UK Government's Department for International Development. The opinions herein are those of the authors and do not necessarily reflect the views of the Department for International Development. 
Conflict of interest: L.M.J. has served as a consultant to PATH. The other authors report no conflict of interest. Authorship: All authors contributed to formulating the research question. L.M.J. drafted the article with J.K. A.P. and A.N. provided critical feedback on the draft. All authors approved the final version. Ethics of buman subject participation: Not applicable.

\section{References}

1. Black RE, Victora CG, Walker SP et al. (2013) Maternal and child undernutrition and overweight in low-income and middle-income countries. Lancet 382, 427-451.

2. Abegunde DO, Mathers CD, Adam T et al. (2007) The burden and costs of chronic diseases in low-income and middle-income countries. Lancet 370, 1929-1938.

3. Dobbs R, Sawers C, Thompson F et al. (2014) Overcoming Obesity: An Initial Economic Analysis. London: McKinsey Global Institute.

4. International Food Policy Research Institute (2016) Global Nutrition Report 2016. From Promise to Impact: Ending Malnutrition by 2030. Washington, DC: IFPRI.

5. Jaacks LM, Slining MM \& Popkin BM (2015) Recent underweight and overweight trends by rural-urban residence among women in low- and middle-income countries. $J$ Nutr 145, 352-357.

6. Jaacks LM, Slining MM \& Popkin BM (2015) Recent trends in the prevalence of under- and overweight among adolescent girls in low- and middle-income countries. Pediatr Obes 10, 428-435.

7. Tzioumis E, Kay MC, Bentley ME et al. (2016) Prevalence and trends in the childhood dual burden of malnutrition in low- and middle-income countries, 1990-2012. Public Health Nutr 19, 1375-1388.

8. World Health Organization (2014) Global Nutrition Targets 2025: Childhood Overweight Policy Brief. Geneva: WHO.

9. Popkin B, Monteiro C \& Swinburn B (2013) Overview: Bellagio Conference on Program and Policy Options for Preventing Obesity in the Low- and Middle-Income Countries. Obes Rev 14, Suppl. 2, 1-8.

10. Swinburn BA, Sacks G, Hall KD et al. (2011) The global obesity pandemic: shaped by global drivers and local environments. Lancet 378, 804-814.

11. Roberto CA, Swinburn B, Hawkes C et al. (2015) Patchy progress on obesity prevention: emerging examples, entrenched barriers, and new thinking. Lancet 385, 2400-2409.

12. Gupta N, Goel K, Shah P et al. (2012) Childhood obesity in developing countries: epidemiology, determinants, and prevention. Endocr Rev 33, 48-70.

13. Olagbuji BN, Olofinbiyi BA, Akintayo AA et al. (2015) Maternal perspectives on gestational weight gain: critical information on developing weight control interventions. Niger Med J 56, 96-102.

14. Kavle J, Mehanna S, Khan G et al. (2014) Cultural Beliefs and Perceptions of Maternal Diet and Weight Gain During Pregnancy and Postpartum Family Planning in Egypt. Washington, DC: US Agency for International Development.

15. Poston L (2012) Maternal obesity, gestational weight gain and diet as determinants of offspring long term health. Best Pract Res Clin Endocrinol Metab 26, 627-639.

16. Yang Z \& Huffman SL (2013) Nutrition in pregnancy and early childhood and associations with obesity in developing countries. Matern Child Nutr 9, 105-119.

17. Christian P \& Stewart CP (2010) Maternal micronutrient deficiency, fetal development, and the risk of chronic disease. J Nutr 140, 437-445.

18. Stein AD, Kahn HS, Rundle A et al. (2007) Anthropometric measures in middle age after exposure to famine during gestation: evidence from the Dutch famine. Am J Clin Nutr 85, 869-876.

19. Stewart CP, Christian P, LeClerq SC et al. (2009) Antenatal supplementation with folic acid+iron + zinc improves linear growth and reduces peripheral adiposity in school-age children in rural Nepal. Am J Clin Nutr 90, 132-140.

20. Iannotti LL, Zavaleta N, Leon Z et al. (2008) Maternal zinc supplementation and growth in Peruvian infants. Am J Clin Nutr 88, 154-160.

21. Darnton-Hill I, Nishida C \& James W (2004) A life course approach to diet, nutrition and the prevention of chronic diseases. Public Health Nutr 7, 101-121.

22. Kuzawa CW, Hallal PC, Adair L et al. (2012) Birth weight, postnatal weight gain, and adult body composition in five low and middle income countries. Am J Hum Biol 24, 5-13.

23. Yajnik C, Lubree H, Rege S et al. (2002) Adiposity and hyperinsulinemia in Indians are present at birth. J Clin Endocrinol Metab 87, 5575-5580.

24. Sachdev HS, Fall CH, Osmond C et al. (2005) Anthropometric indicators of body composition in young adults: relation to size at birth and serial measurements of body mass index in childhood in the New Delhi birth cohort. Am J Clin Nutr 82, 456-466.

25. Ong KK \& Loos RJ (2006) Rapid infancy weight gain and subsequent obesity: systematic reviews and hopeful suggestions. Acta Paediatr 95, 904-908.

26. Adair LS, Fall CH, Osmond C et al. (2013) Associations of linear growth and relative weight gain during early life with adult health and human capital in countries of low and middle income: findings from five birth cohort studies. Lancet 382, 525-534.

27. Victora CG, Adair L, Fall C et al. (2008) Maternal and child undernutrition: consequences for adult health and human capital. Lancet 371, 340-357.

28. Li H, Stein AD, Barnhart HX et al. (2003) Associations between prenatal and postnatal growth and adult body size and composition. Am J Clin Nutr 77, 1498-1505.

29. Horta BL, World Health Organization (2007) Evidence on the Long-Term Effects of Breastfeeding. Geneva: WHO.

30. Casazza K, Fernandez JR \& Allison DB (2012) Modest protective effects of breast-feeding on obesity: is the evidence truly supportive? Nutr Today 47, 33-38.

31. Kramer MS, Matush L, Vanilovich I et al. (2007) Effects of prolonged and exclusive breastfeeding on child height, weight, adiposity, and blood pressure at age $6.5 \mathrm{y}$ : evidence from a large randomized trial. Am J Clin Nutr 86, 1717-1721.

32. Brion M-JA, Lawlor DA, Matijasevich A et al. (2011) What are the causal effects of breastfeeding on IQ, obesity and blood pressure? Evidence from comparing high-income with middleincome cohorts. Int J Epidemiol 40, 670-680.

33. Caleyachetty A, Krishnaveni GV, Veena SR et al. (2013) Breastfeeding duration, age of starting solids and high BMI risk and adiposity in Indian children. Matern Cbild Nutr $\mathbf{9}$, 199-216.

34. World Health Organization (2013) Short-Term Effects of Breastfeeding: A Systematic Review on the Benefits of Breastfeeding on Diarrboea and Pneumonia Mortality. Geneva: WHO.

35. World Health Organization \& UNICEF (2003) Global Strategy for Infant and Young Child Feeding. Geneva: WHO.

36. Bankole O, Aderinokun G, Odenloye O et al. (2006) Weaning practices among some Nigerian women: implication on oral health. Odontostomatol Trop 29, 15-21.

37. Kimani-Murage EW, Madise NJ, Fotso J-C et al. (2011) Patterns and determinants of breastfeeding and complementary feeding practices in urban informal settlements, Nairobi Kenya. BMC Public Health 11, 396.

38. Koletzko B, von Kries R, Closa R et al. (2009) Lower protein in infant formula is associated with lower weight up to age $2 \mathrm{y}$ : a randomized clinical trial. Am J Clin Nutr 89, 1836-1845. 
39. Singhal A, Kennedy K, Lanigan J et al. (2010) Nutrition in infancy and long-term risk of obesity: evidence from 2 randomized controlled trials. Am J Clin Nutr 92, 1133-1144.

40. Daivadanam M, Wahlström R, Thankappan K et al. (2015) Balancing expectations amidst limitations: the dynamics of food decision-making in rural Kerala. BMC Public Health 15, 644 .

41. Akpan E \& Ekpenyong C (2013) Urbanization drift and obesity epidemic in Sub-Saharan Africa: a review of the situation in Nigeria. Eur J Sustain Dev 2, 141-164.

42. Kavle JA, Mehanna S, Saleh G et al. (2015) Exploring why junk foods are 'essential' foods and how culturally tailored recommendations improved feeding in Egyptian children. Matern Child Nutr 11, 346-370.

43. Espeut D TE, Coffey C, Nyaku A et al. (2016) A Multi-Stage Analysis on Key Determinants of Malnutrition in Cambodia. Washington, DC: Maximizing the Quality of Scaling Up Nutrition Project (MQSUN), PATH.

44. Bhanji S, Khuwaja AK, Siddiqui F et al. (2011) Underestimation of weight and its associated factors among overweight and obese adults in Pakistan: a cross sectional study. BMC Public Health 11, 363

45. Saleem MD, Ahmed G, Mulla J et al. (2013) Weight misperception amongst youth of a developing country: Pakistan-a cross-sectional study. BMC Public Health 13, 707.

46. Sirang Z, Bashir HH, Jalil B et al. (2013) Weight patterns and perceptions among female university students of Karachi: a cross sectional study. BMC Public Health 13, 230.

47. Kruger HS, Puoane T, Senekal M et al. (2005) Obesity in South Africa: challenges for government and health professionals. Public Health Nutr 8, 491-500.

48. World Health Organization (2013) Global Action Plan for the Prevention and Control of Noncommunicable Diseases 2013-2020. Geneva: WHO.

49. World Health Organization (2012) Population-Based Approaches to Childhood Obesity Prevention. Geneva: WHO.

50. World Health Organization (2009) Interventions on Diet and Physical Activity: What Works: Summary Report. Geneva: WHO.

51. Sunguya BF, Ong KI, Dhakal S et al. (2014) Strong nutrition governance is a key to addressing nutrition transition in low and middle-income countries: review of countries' nutrition policies. Nutr J 13, 65.

52. World Health Organization (2006) Marketing of Food and Non-Alcoholic Beverages to Children. Geneva: WHO.

53. Hawkes C \& Lobstein T (2011) Regulating the commercial promotion of food to children: a survey of actions worldwide. Int J Pediatr Obes 6, 83-94.

54. Silva AC, Bortolini GA \& Jaime PC (2013) Brazil's national programs targeting childhood obesity prevention. Int J Obes Suppl 3, Suppl. 1, S9-S11.

55. Igumbor EU, Sanders D, Puoane TR et al. (2012) 'Big food', the consumer food environment, health, and the policy response in South Africa. PLoS Med 9, e1001253.

56. World Health Organization \& UNICEF (2016) Marketing of Breast-Milk Substitutes: National Implementation of the International Code. Status Report 2016. Geneva: WHO.

57. Lutter CK (2013) The International Code of Marketing of Breast-milk Substitutes: lessons learned and implications for the regulation of marketing of foods and beverages to children. Public Health Nutr 16, 1879-1884.

58. Adams J, Tyrrell R, Adamson AJ et al. (2012) Effect of restrictions on television food advertising to children on exposure to advertisements for 'less healthy' foods: repeat cross-sectional study. PLoS One 7, e31578.
59. Hawkes C, Jewell J \& Allen K (2013) A food policy package for healthy diets and the prevention of obesity and diet-related non-communicable diseases: the NOURISHING framework. Obes Rev 14, 159-168.

60. Lachat C, Otchere S, Roberfroid D et al. (2013) Diet and physical activity for the prevention of noncommunicable diseases in low-and middle-income countries: a systematic policy review. PLoS Med 10, e1001465.

61. Ministry of Health of Brazil (2014) Dietary Guidelines for the Brazilian Population. Brasilia: Ministry of Health of Brazil.

62. Rwanda Ministry of Health (2008-2009) Regenerative Health \& Nutrition (RHNP): About. http://rhnp.gov.gh/ about.php?id=0004\& (accessed August 2015).

63. Tagoe HA \& Dake FA (2011) Healthy lifestyle behaviour among Ghanaian adults in the phase of a health policy change. Global Health 7, 7.

64. Sacks G, Rayner M \& Swinburn B (2009) Impact of front-of-pack 'traffic-light' nutrition labelling on consumer food purchases in the UK. Health Promot Int 24, 344-352.

65. Verstraeten R, Roberfroid D, Lachat C et al. (2012) Effectiveness of preventive school-based obesity interventions in low- and middle-income countries: a systematic review. Am J Clin Nutr 96, 415-438.

66. World Health Organization/UNICEF/Food and Agriculture Organization of the United Nations (2006) NutritionFriendly School Initiative. Part I: Conceptual Framework. Part II: Self-Appraisal Tool. Geneva: WHO.

67. Delisle HF, Receveur O, Agueh V et al. (2013) Pilot project of the Nutrition-Friendly School Initiative (NFSI) in Ouagadougou, Burkina Faso and Cotonou, Benin, in West Africa. Glob Health Promot 20, 39-49.

68. Parmar A (2009) Nutrition-Friendly School Initiative - The Indian experience. New Delhi: HRIDAY-SHAN.

69. Shah P, Misra A, Gupta N et al. (2010) Improvement in nutrition-related knowledge and behaviour of urban Asian Indian school children: findings from the "Medical education for children/Adolescents for Realistic prevention of obesity and diabetes and for healthy aGeing' (MARG) intervention study. Br J Nutr 104, 427-436.

70. Food and Agriculture Organization of the United Nations (2014) Scaling-Up Purchase from Africans for Africa: Family Farmers Supply Nutritious Meals for School Children. Rome: FAO.

71. World Food Programme (2014) Improving links between smallholder farmers and school feeding programmes. https:// www.wfp.org/purchase-progress/news/blog/p4p-improveslinks-between-small-scale-farmers-and-school-feeding-progra (accessed September 2015).

72. Duda RB, Jumah NA, Hill AG et al. (2006) Interest in healthy living outweighs presumed cultural norms for obesity for Ghanaian women. Health Qual Life Out 4, 44.

73. US Agency for International Development (2016) Maternal and Child Survival Program (MCSP) Nutrition Brief: Junk Food Consumption is a Nutrition Problem among Infants and Young Children: Evidence and Program Considerations for Low and Middle Income Countries. Washington, DC: USAID.

74. Yaktine AL \& Rasmussen KM (2009) Weight Gain During Pregnancy: Reexamining the Guidelines. Washington, DC: National Academies Press.

75. Uauy R \& Kain J (2002) The epidemiological transition: need to incorporate obesity prevention into nutrition programmes. Public Health Nutr 5, 223-229.

76. Huybregts L, Roberfroid D, Lanou H et al. (2013) Prenatal lipid-based nutrient supplements increase cord leptin concentration in pregnant women from rural Burkina Faso. J Nutr 143, 576-583. 